\title{
On the number of trials necessary for stabilization of error-related brain activity across the life span
}

\author{
MATTHEW B. PONTIFEX, ${ }^{\mathrm{a}}$ MARK R. SCUDDER, ${ }^{\mathrm{a}}$ MICHAEL L. BROWN, ${ }^{\mathrm{a}}$ KEVIN C. \\ O'LEARY, ${ }^{\mathrm{a}}$ CHIEN-TING WU, ${ }^{\mathrm{a}}$ JASON R. THEMANSON, ${ }^{\mathrm{b}}$ AND CHARLES H. HILLMAN ${ }^{\mathrm{a}}$ \\ ${ }^{a}$ Department of Kinesiology \& Community Health, University of Illinois at Urbana-Champaign, Urbana, Illinois, USA \\ ${ }^{\mathrm{b}}$ Department of Psychology, Illinois Wesleyan University, Bloomington, Illinois, USA
}

\begin{abstract}
The minimum number of trials necessary to accurately characterize the error-related negativity (ERN) and the error positivity (Pe) across the life span was investigated using samples of preadolescent children, college-age young adults, and older adults. Event-related potentials and task performance were subsequently measured during a modified flanker task. Response-locked averages were created using sequentially increasing errors of commission in blocks of two. Findings indicated that across all age cohorts ERN and Pe were not significantly different relative to the withinparticipants grand average after six trials. Further, results indicated that the ERN and Pe exhibited excellent internal reliability in preadolescent children and young adults after six trials, but older adults required eight trials to reach similar reliability. These data indicate that the ERN and Pe may be accurately quantified with as few as six to eight commission error trials across the life span.
\end{abstract}

Descriptors: Cognition, Children, Normal Volunteers, Aged, EEG/ERP

With a growing number of investigations assessing neuroelectric concomitants of error-related brain activity, it is increasingly necessary to quantify the number of trials needed to obtain stable and reliable event-related potential (ERP) components. During the past decade the minimum number of trials necessary for response-locked ERP components has been fiercely debated, with averages ranging from 5 to 300 trials (Olvet \& Hajcak, 2009). Recently, Olvet and Hajcak have elucidated this issue by systematically assessing the stability of the error-related responselocked ERP components in young adults, indicating that stability occurs following six to eight error trials. Still unanswered, however, is the extent to which these findings generalize across the life span. That is, given the high level of intraindividual variability present during development and aging (Hultsch \& MacDonald, 2004; Siegler, 1994) as well as the increased interest in assessing error-related brain activity in these populations (Davies, Segalowitz, \& Gavin, 2004; Falkenstein, Hoormann, \& Hohnsbein, 2001; Hillman, Buck, Themanson, Pontifex, \& Castelli, 2009; Liotti, Pliszka, Perez, Kothmann, \& Woldorff, 2005; Mathalon et al., 2003; Mathewson, Dywan, \& Segalowitz, 2005; Nieuwenhuis et al., 2002; Santesso, Segalowitz, \& Schmidt, 2006;

Support for our research and the preparation of this article were provided by grants from the National Institute of Mental Health (F31 MH076463) to Jason Themanson as well as the National Institute of Child Health and Human Development (RO1 HD060385) and the National Institute on Aging (RO1 AG021188) to Charles Hillman.

Address reprint requests to: Charles H. Hillman, Ph.D., Department of Kinesiology \& Community Health, 317 Louise Freer Hall, 906 South Goodwin Avenue, University of Illinois, Urbana, IL 61801, USA. E-mail: chhillma@illinois.edu
Themanson, Hillman, \& Curtin, 2006; Themanson et al., 2008; Wiersema, van der Meere, \& Roeyers, 2007), further research is necessary to determine the stability of error-related brain activity across the life span.

The vast majority of work on error-related brain activity has focused on the error-related negativity (ERN) and error positivity (Pe). The ERN (also known as the $\mathrm{N}_{\mathrm{e}}$; Falkenstein, Hohnsbein, Hoormann, \& Blanke, 1991) is a negative-going response-locked ERP component that occurs approximately $50 \mathrm{~ms}$ following errors of commission and exhibits maximum amplitude over the midline fronto-central recording sites (Falkenstein et al., 1991; Gehring, Goss, Coles, Meyer, \& Donchin, 1993). A variety of neuroimaging methods (i.e., dipole localization, functional magnetic resonance imaging, and magnetoencephalography) have localized the generator of the ERN to be at or very near the dorsal portion of the anterior cingulate cortex (ACC; Carter et al., 1998; Dehaene, Posner, \& Tucker, 1994; Miltner et al., 2003; van Veen \& Carter, 2002). Despite debate over the functional significance of the ERN (i.e., Botvinick, Braver, Barch, Carter, \& Cohen, 2001: conflict monitoring process vs. Holroyd \& Coles, 2002: reinforcement learning model), the ERN is generally believed to reflect activation of top-down compensatory processes in support of erroneous behaviors regardless of an individual's awareness of the error (Gehring \& Knight, 2000; Nieuwenhuis, Ridderinkhof, Blom, Band, \& Kok, 2001). Following the ERN, the Pe is a positive-going response-locked ERP component that occurs approximately 200-600 ms following errors of commission (Falkenstein, Hohnsbein, Hoormann, \& Blanke, 1990; Falkenstein, Hoormann, Christ, \& Hohnsbein, 2000; Ridderinkhof, Ramautar, \& Wijnen, 2009). The Pe presents with a diffuse scalp distribution, which 
exhibits maximum amplitude over midline centro-parietal recording sites (Falkenstein et al., 1990, 2000; Ridderinkhof et al., 2009). The ERN and Pe are thought to reflect different aspects of error processing (Herrmann, Römmler, Ehlis, Heidrich, \& Fallgatter, 2004), with the Pe being localized to a neuronal generator in the ACC separate from that of the ERN (Herrmann et al., 2004; Overbeek, Nieuwenhuis, \& Ridderinkhof, 2005; van Veen \& Carter, 2002). The Pe is believed to represent a neuroelectric index of the allocation of attention toward an erroneous response (Mathewson et al., 2005), the conscious recognition of an error (Endrass, Reuter, \& Kathmann, 2007; Nieuwenhuis et al., 2001), the postresponse evaluation of an error (Davies, Segalowitz, Dywan, \& Pailing, 2001; Falkenstein et al., 1990), or an emotional reaction to the commission of an error (Falkenstein et al., 2000; van Veen \& Carter, 2002).

The present study sought to assess the stability of the ERN and Pe potentials across the life span, extending prior research in young adults (Olvet \& Hajcak, 2009), which has demonstrated that a minimum of six to eight error of commission trials were necessary to obtain stable ERN and Pe components. Toward this end, a modified flanker task was used to elicit a large number of commission errors in samples of preadolescent children, young adults, and older adults from which response-locked averages were created using sequentially increasing trials in blocks of two $(1-2,1-4,1-6$, etc.). This methodology is similar to that in previous reports aimed at determining the minimum number of trials needed for stability of the ERN/Pe (Olvet \& Hajcak, 2009) and P3 (Cohen \& Polich, 1997) components. It was hypothesized that preadolescent children and older adults would require a greater number of trials to stabilize the ERN and Pe components relative to young adults because of the increased intraindividual variability commonly observed in these populations.

\section{Method}

\section{Participants}

A total of 225 participants, comprised of 79 preadolescent children, 68 college-age young adults, and 78 older adults, were recruited from the east-central Illinois region. Young and older adult participants and the legal guardians of the preadolescent child participants provided written informed consent. Preadolescent participants provided written assent in accordance with the Institutional Review Board of the University of Illinois at UrbanaChampaign. All participants reported being free of neurological disorders, cardiovascular disease, any medications that influence central nervous system function, and had (corrected to) normal vision based on the minimal 20/20 standard. Participants who made less than 14 errors were discarded from all analyses (Olvet \& Hajcak, 2009), leaving a total of 139 participants, comprised of 56 preadolescent children ( 24 female), 57 college-age young adults ( 34 female), and 26 older adults (12 female). Table 1 summarizes the participant characteristics by age cohort.

\section{Task}

Participants completed a modified version of the Eriksen flanker task (Eriksen \& Eriksen, 1974), in which participant were instructed to respond as accurately as possible to the direction of a centrally presented arrow amid either congruous (e.g., $<<<<<$ or $>>>>>$ ) or incongruous (e.g., $<<><<$ or $>><>>$ ) flanking arrows (Hillman et al., 2006; Pontifex \& Hillman, 2007). To reduce the influence of floor and ceiling effects, task parameters were modified for each cohort. In all cases, however, the task was counterbalanced to provide equiprobable
Table 1. Mean (+1 SD) Participant Characteristics by Age Cohort

\begin{tabular}{lccc}
\hline \hline & $\begin{array}{c}\text { Preadolescent } \\
\text { children }\end{array}$ & Young adults & Older adults \\
\hline$N$ & $56(24$ girls $)$ & $57(34$ women $)$ & $26(12$ women $)$ \\
$\begin{array}{l}\text { Age (years) } \\
\text { Age range (years) }\end{array}$ & $9.6 \pm 0.8$ & $19.9 \pm 1.6$ & $65.7 \pm 4.2$ \\
$\begin{array}{l}\text { Errors of } \\
\text { commission }\end{array}$ & $26.7 \pm 13.3$ & $38.5 \pm 25.8$ & $24.6 \pm 12.1$ \\
$\begin{array}{l}\text { Error of } \\
\text { commission, Range }\end{array}$ & $14-85$ & $14-156$ & $14-67$ \\
$\begin{array}{l}\text { Response accuracy } \\
\text { (\% correct) }\end{array}$ & $73.0 \pm 12.3$ & $85.4 \pm 8.9$ & $84.2 \pm 8.3$ \\
$\begin{array}{l}\text { Reaction time (ms) } \\
521.3 \pm 102.1\end{array}$ & $386.0 \pm 37.6$ & $446.5 \pm 69.5$ \\
\hline \hline
\end{tabular}

congruency and directionality. Preadolescent children were administered two blocks of 100 trials, with stimuli presented focally for $200 \mathrm{~ms}$ with a fixed interstimulus interval of $1700 \mathrm{~ms}$. Young adults received two blocks of 300 trials, with stimuli presented focally for $80 \mathrm{~ms}$ with a variable interstimulus interval of 1000 $1400 \mathrm{~ms}$. Lastly, older adults were administered two blocks of 257 trials, with stimuli presented focally for $100 \mathrm{~ms}$ with a fixed interstimulus interval of $1100 \mathrm{~ms}$.

\section{ERP Recording}

Electroencephalographic (EEG) activity was recorded from 64 electrode sites (FPz, Fz, FCz, Cz, CPz, Pz, POz, Oz, FP1/2, F7/5/3/ 1/2/4/6/8, FT7/8, FC3/1/2/4, T7/8, C5/3/1/2/4/6, M1/2, TP7/8, $\mathrm{CB} 1 / 2, \mathrm{P} 7 / 5 / 3 / 1 / 2 / 4 / 6 / 8, \mathrm{PO} 7 / 5 / 3 / 4 / 6 / 8, \mathrm{O} 1 / 2)$ arranged in an extended montage based on the International 10-10 system (Chatrian, Lettich, \& Nelson, 1985), using a Neuroscan Quik-cap (Compumedics, Inc., Charlotte, NC). Recordings were referenced to averaged mastoids (M1, M2), with AFz serving as the ground electrode and impedance less than $10 \mathrm{k} \Omega$. Additional electrodes were placed above and below the left orbit and on the outer canthus of each eye to monitor electrooculographic (EOG) activity with a bipolar recording. Continuous data were digitized at a sampling rate of 500 $\mathrm{Hz}$, amplified 500 times with a DC to $70-\mathrm{Hz}$ filter, and a $60-\mathrm{Hz}$ notch filter using a Neuroscan Synamps 2 amplifier. Continuous data were corrected off-line for EOG artifacts using a spatial filter (Compumedics Neuroscan, 2003). Epochs were created from -600 to $1000 \mathrm{~ms}$ around the response, baseline corrected using the -400 to -200 -ms preresponse period (Olvet \& Hajcak, 2009) and filtered using a zero phase shift $1-\mathrm{Hz}(24 \mathrm{~dB} /$ octave) to $12-\mathrm{Hz}$ ( $24 \mathrm{~dB} /$ octave) band-pass filter. Trials with an error of omission or artifact exceeding $\pm 75 \mu \mathrm{V}$ were rejected. For all analyses, response-locked averages were created based on a sequentially increasing subset of 2, 4, 6, 8, 10, and 12 errors of commission from each participant and a within-participant grand average of all error of commission trials (range: 14-156 trials; Cohen, \& Polich, 1997; Olvet \& Hajcak, 2009). The ERN and Pe were evaluated as the average activity in a $0-100$-ms and $200-400$-ms window relative to the response, respectively (Olvet \& Hajcak, 2009).

\section{Procedure}

Following completion of the informed consent, participants were fitted with a 64-channel Quik-cap (Compumedics Neuroscan, Inc.) and provided with task instructions. Participants were given the opportunity to ask questions prior to completing 20 practice trials. During the practice session, the experimenter observed 

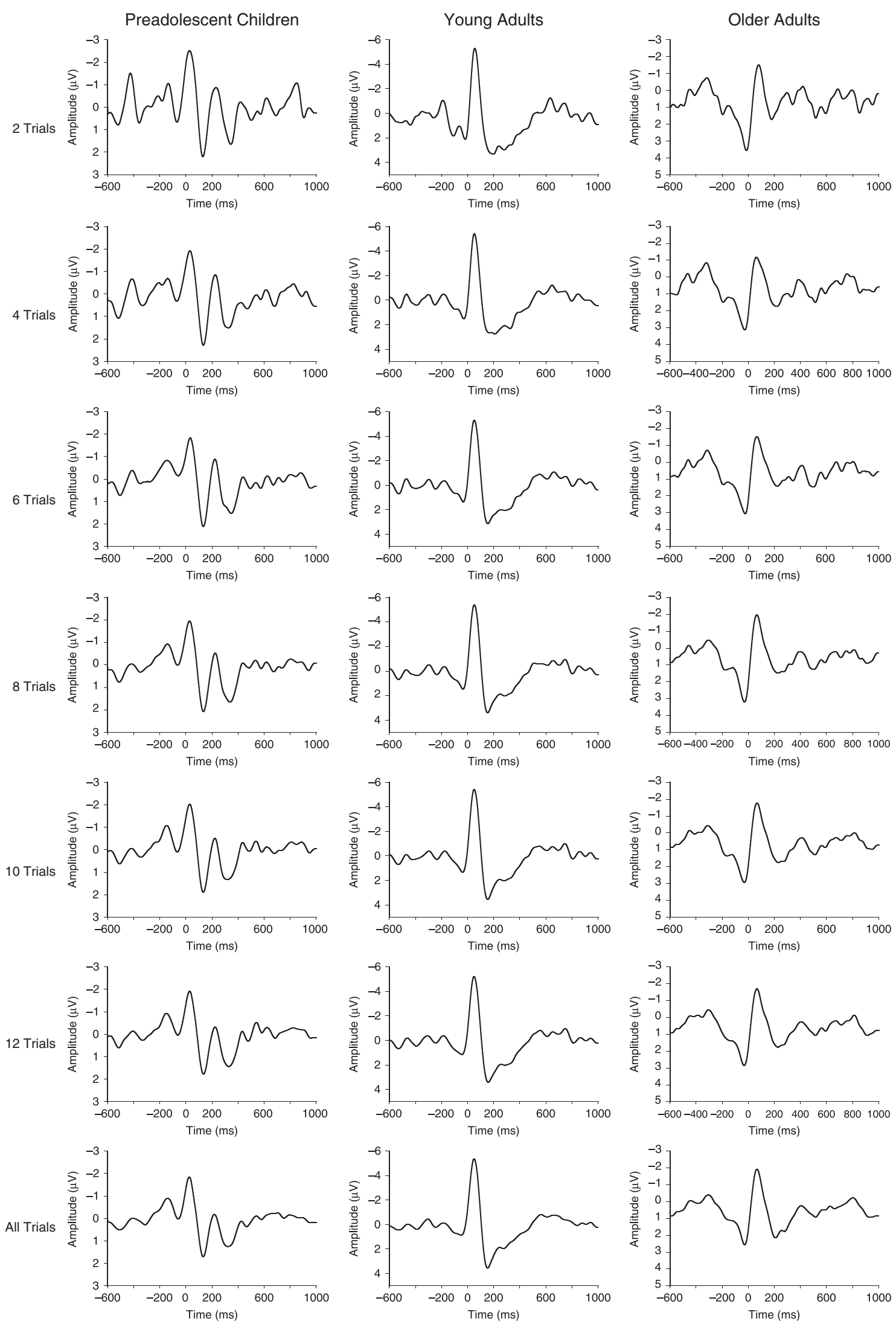

Figure 1. Grand average ERN waveforms at FCz for each age cohort for 2, 4, 6, 8, 10, 12, and all trials. 

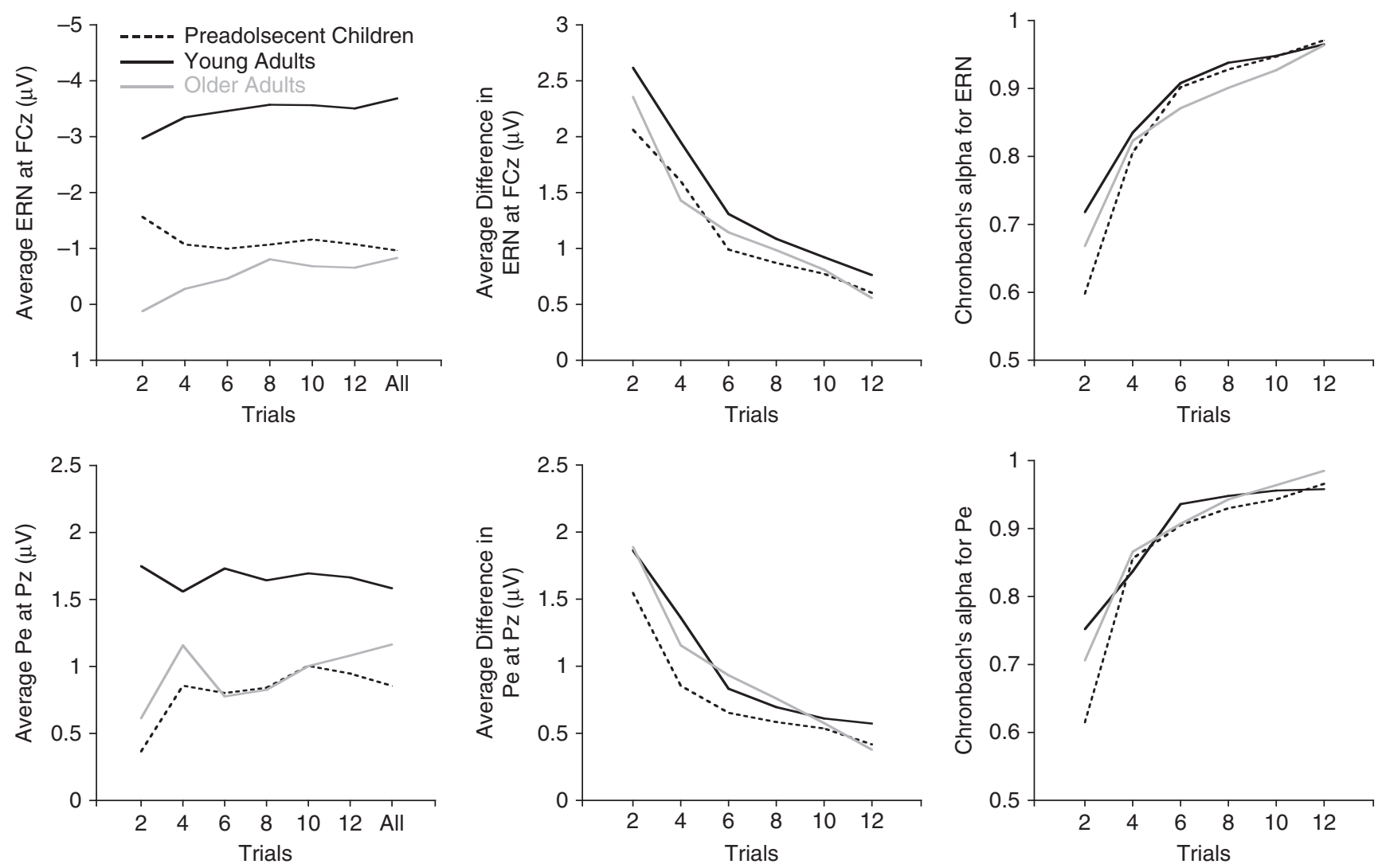

Figure 2. Average amplitude (left), average amplitude difference score (calculated by taking the absolute value of the difference between the withinparticipant grand average and each of the successive trial averages; middle), and Chronbach's alpha (right) for ERN at the FCz electrode site (top) and $\mathrm{Pe}$ at the Pz electrode site (bottom) by number of trials for each age cohort.

task performance to ensure that the participant understood the task. If a participant's task performance was below $60 \%$, another block of 20 practice trials was administered.

\section{Statistical Analysis}

All statistical analyses were conducted using a significance level of $p=.05$, and analyses with three or more within-subjects levels used the Greenhouse-Geisser statistic with Bonferroni corrected $t$ tests for post hoc comparisons. Analyses were conducted separately for each age cohort. The stability of the ERN and Pe components were assessed in three ways. First, analyses were conducted for ERN at the FCz electrode site and Pe at the Pz electrode site (Olvet \& Hajcak, 2009) using a one factor repeated-measures analysis of variance (ANOVA) on the average amplitude within the designated windows for each average $(2,4,6,8,10,12$, and grand average). Next, given that this investigation was specifically designed to assess the extent to which each successive average differed (without regard to direction) from the grand average, relative measures of stability were calculated by taking the absolute value of the difference between the average amplitude for the within-participant grand average (GA) and each of the successive averages to create a difference score (|GA-2|, |GA-4|, |GA-6|, |GA-8|, |GA-10|, |GA-12|). These difference scores were then submitted to a one-factor repeated-measures ANOVA. Finally, Chronbach's alpha was used to quantify the internal reliability (excellent reliability: $>.9$, high reliability: $>.7$, moderate reliability: > .5; Hinton, Brownlow, McMurray, \& Cozens, 2004) of the ERN and Pe as a function of increasing trial numbers relative to the within-participant grand average (Olvet \& Hajcak, 2009).

\section{Results}

ERN

Figure 1 illustrates the grand-average ERP waveform at the $\mathrm{FCz}$ electrode site for each age cohort for 2, 4, 6, 8, 10, 12, and all trials. The omnibus analyses of the mean amplitude for 2, 4, 6, 8, 10, 12, and all trials within each age cohort revealed no significant differences in mean amplitude as a function of the number of trials for any of the three age cohorts: preadolescent children: $F(6,50)=0.8$, $p=.41, \eta^{2}=.01$; young adults: $F(6,51)=1.4, p=.26, \eta^{2}=.02$; older adults: $F(6,20)=1.6, p=.20, \eta^{2}=.06$ (see Figure 2). Analyses of the difference scores yielded a main effect for the number of trials within each of the three age cohorts: preadolescent children: $F(5,51)=10.0, p=.001, \eta^{2}=.15$; young adults: $F(5,52)=23.5$, $p<.001, \eta^{2}=.3$; older adults: $F(5,21)=9.4, p<.001, \eta^{2}=.27$. Across each cohort, after 6 trials, post hoc analyses revealed no significant differences following Bonferroni correction $(p=.003)$ between the absolute value of the difference between the withinparticipant grand average and each of the successive trial averages: preadolescent children: $t(55) \leq 2.9, p \geq .005$; young adults: $t(56) \leq 2.7, p \geq .008$; older adults: $t(25) \leq 3.0, p \geq .006$ (see Figure 2). For preadolescent children and young adults, Chronbach's alpha ranged from .598 to .971 and exceeded .9 (suggesting excellent reliability) for averages with $6,8,10$, and 12 trials. For older adults, Chronbach's alpha ranged from .668 to .964 and exceeded .9 for averages with 8, 10, and 12 trials (Figure 2).

Pe

Figure 3 illustrates the grand average ERP waveform at the $\mathrm{Pz}$ electrode site for each age cohort for 2, 4, 6, 8, 10, 12, and all trials. 

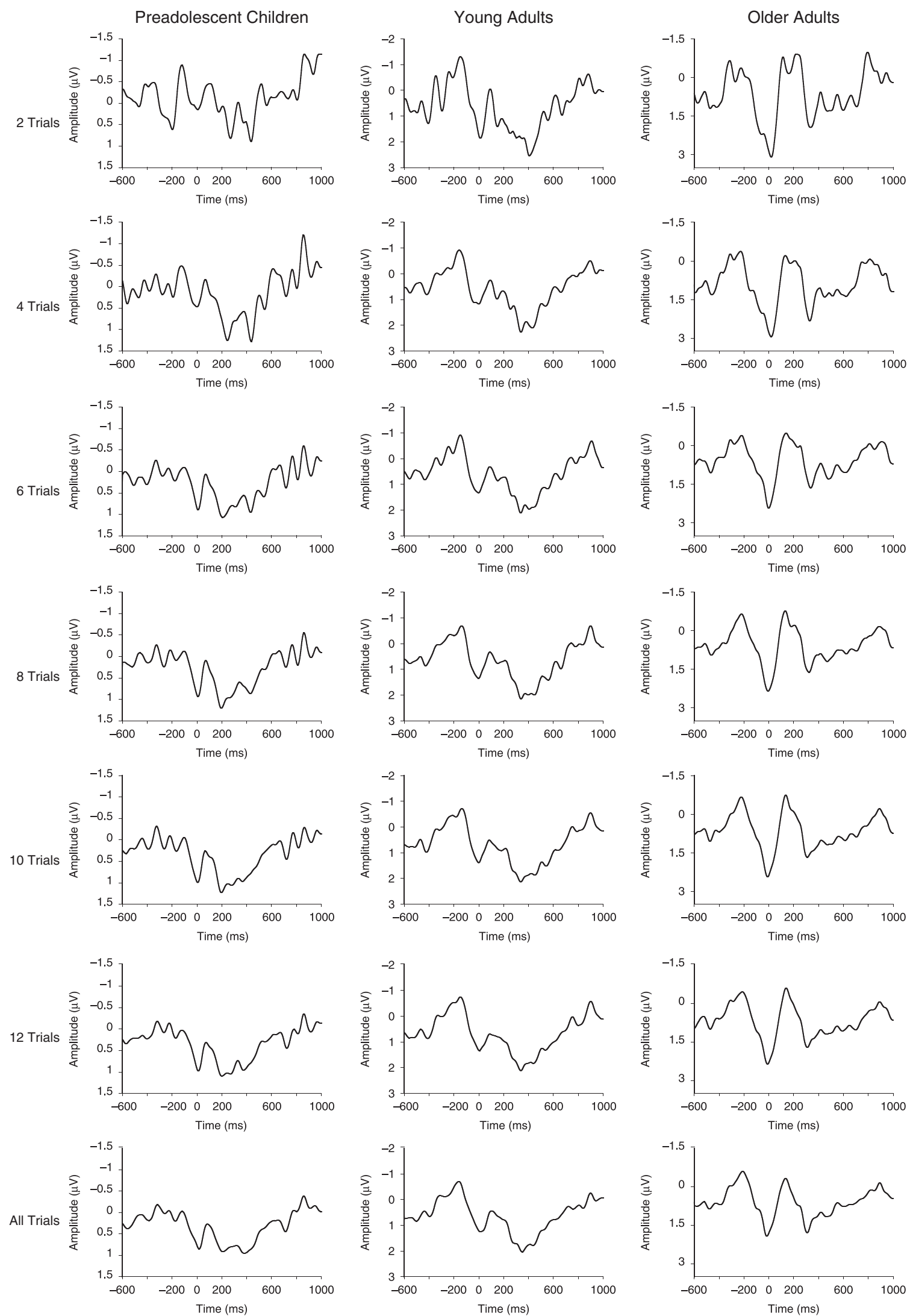

Figure 3. Grand average Pe waveforms at $\mathrm{Pz}$ for each age cohort for 2, 4, 6, 8, 10, 12, and all trials. 
For preadolescent children, the omnibus analyses of the mean amplitude for 2, 4, 6, 8, 10,12, and all trials revealed a main effect, $F(6,50)=3.2, p<.04, \eta^{2}=.055$; however, post hoc analyses revealed no significant differences following Bonferroni correction $(p=.002)$ between the mean amplitude for each successive trial average, $t(55) \leq 3.0, p \geq .004$ (see Figure 2). For young adults and older adults, the omnibus analyses revealed no significant differences in mean amplitude as a function of the number of trials: young adults: $F(6,51)=0.2, \quad p=.8, \eta^{2}=.004$; older adults: $F(6,20)=1.1, p=.35, \eta^{2}=.04$ (see Figure 2). Analyses of the difference scores yielded a main effect for the number of trials for each of the three age cohorts: preadolescent children: $F(5,51)=22.4, p<.001, \eta^{2}=.29$; young adults: $F(5,52)=21.2$, $p<.001, \eta^{2}=.28$; older adults: $F(5,21)=14.5, p<.001, \eta^{2}=.37$. Across each cohort, after 6 trials, post hoc analyses revealed no significant differences following Bonferroni correction $(p=.003)$ between the absolute value of the difference between the withinparticipant grand average and each of the successive trial averages: preadolescent children: $t(55) \leq 2.8, p \geq .006$; young adults: $t(25) \leq 3.2, p \geq .004$; older adults: $t(56) \leq 2.9, p \geq .005$ (see Figure 2). For all cohorts, Chronbach's alpha ranged from .615 to .985 and exceeded .9 for averages with 6, 8, 10, and 12 trials (Figure 2).

\section{Discussion}

The current findings suggest through multiple convergent analyses that error-related brain activity stabilizes following six to eight trials, with nonsignificant changes occurring with the inclusion of additional trials. That is, for the ERN component the difference in mean amplitude between the grand average and each of the successive trial averages did not differ significantly after six trials regardless of cohort. Further, an analysis of internal reliability provides additional support with excellent internal reliability relative to the grand average observed for preadolescent children and young adults following six trials and for older adults following eight trials. Similarly, for the Pe component across all age cohorts, no significant differences were observed after six trials for the difference in mean amplitude between the grand average and each of the successive trial averages. Excellent internal reliability relative to the grand average was also observed after six trials for each cohort.

The findings presented herein are consistent with previous findings in young adults (Olvet \& Hajcak, 2009), which observed stabilization of error-related brain activity following six to eight trials. Novel to this investigation, however, is the extension to developing and aging populations. Collectively, these findings suggest that the stability of the ERN and Pe components is independent of age and component amplitude. Given the high level of intraindividual variability present in these participant populations (Hultsch \& MacDonald, 2004; Siegler, 1994), the finding that error-related brain activity can be accurately quantified with as few as six to eight trials provides consideration regarding the reliability and validity for assessing such covert measures of error commission in these populations. Further, the necessity of a smaller number of minimum trials allows for the inclusion of additional participants, providing a more accurate representation of the participant population. Within the context of the present investigation, a cutoff of 14 errors of commission resulted in considerable data loss, with only $\approx 71 \%$ of the preadolescent children and only $\approx 36 \%$ of the older adults demonstrating enough error trials for inclusion. However, using a substantially smaller cutoff of six trials for preadolescent children and eight trials for older adults resulted in considerable data savings, with $\approx 95 \%$ and $\approx 71 \%$ of the participant samples included, respectively.

In these contexts, the requirement of a minimum of six to eight errors of commission also allows for the investigation of error-related brain activity in response to tasks or task conditions in which errors of commission occur more infrequently. It is important to note that these numbers reflect the minimum criteria required for accurate representation of error-related brain activity and that a larger number of errors of commission may provide increased reliability and signal-to-noise ratio. Additional research is necessary to elucidate the stability of the ERN and Pe components in response to other tasks and task parameters. To this end, one limitation of the present investigation was that minor differences in task parameters may have contributed to the slight differences in ERN stability across age cohorts. Despite the relative stability across age cohorts for the number of trials necessary to accurately quantify error-related brain activity, the stability of the ERN and Pe components in other specialized or clinical participant populations remains an open question. However, preliminary data in a sample of college-age young adults with a history of mild traumatic brain injury replicates the findings presented herein and suggests that error-related brain activity may be accurately quantified in this populations with as few as six to eight errors of commission trials. ${ }^{1}$ Taken together, the results of the present study suggest that the ERN and Pe components remain relatively stable using a minimum of six to eight error of commission trials across the life span.

\section{REFERENCES}

Botvinick, M. M., Braver, T. S., Barch, D. M., Carter, C. S., \& Cohen, J. D. (2001). Conflict monitoring and cognitive control. Psychological Review, 108, 624-652.

Carter, C. S., Braver, T. S., Barch, D. M., Botvinick, M. M., Noll, D., \& Cohen, J. D. (1998). Anterior cingulated cortex, error detection, and the online monitoring of performance. Science, 280, 747-749.

Chatrian, G. E., Lettich, E., \& Nelson, P. L. (1985). Ten percent electrode system for topographic studies of spontaneous and evoked EEG activity. American Journal of EEG Technology, 25, 83-92.

Cohen, J., \& Polich, J. (1997). On the number of trials needed for P300. International Journal of Psychophysiology, 25, 249-255.

Compumedics Neuroscan (2003). Offline analysis of acquired data (SCAN 4.3-Vol. II, EDIT 4.3). [Software Manual]. El Paso, TX: Author.

Davies, P. L., Segalowitz, S. J., Dywan, J., \& Pailing, P. E. (2001). Errornegativity and positivity as they relate to other ERP indices of attentional control and stimulus processing. Biological Psychology, 56, 191-206.
Davies, P. L., Segalowitz, S. J., \& Gavin, W. J. (2004). Development of response monitoring ERPs in 7- to 25-year-olds. Developmental Neuropsychology, 25, 355-376.

${ }^{1} n=19$. Omnibus analyses of mean amplitude revealed no significant differences: ERN: $F(6,13)=1.6, p=.22, \eta^{2}=.08$; Pe: $F(6,13)=2.1$, $p=.15, \eta^{2}=.11$. Analyses of the difference scores yielded a main effect for the number of trials: ERN: $F(5,14)=14.9, p<.001, \eta^{2}=.45$; Pe: $F(5,14)=4.1, p=.04, \eta^{2}=.32$. After six trials, post hoc analyses revealed no significant differences following Bonferroni correction $(p=.003)$ between the absolute value of the difference between the within-participant grand average and each of the successive trial averages: ERN: $t(18) \leq 3.3, p \geq .004$; Pe: $t(18) \leq 2.1, p \geq .006$. For ERN, Chronbach's alpha ranged from .641 to .989 and exceeded .9 for averages with 8,10 , and 12 trials. For Pe, Chronbach's alpha ranged from .658 to .984 and exceeded .9 for averages with $6,8,10$, and 12 trials. 
Dehaene, S., Posner, M. I., \& Tucker, D. M. (1994). Localization of a neural system for error detection and compensation. Psychological Science, 5, 303-305.

Endrass, T., Reuter, B., \& Kathmann, N. (2007). ERP correlates of conscious error recognition: Aware and unaware errors in an antisaccade task. European Journal of Neuroscience, 26, 1714-1720.

Eriksen, C. W., \& Eriksen, B. A. (1974). Effects of noise letters upon the identification of a target letter in a non-search task. Perception and Psychophysics, 16, 143-149.

Falkenstein, M., Hohnsbein, J., Hoormann, J., \& Blanke, L. (1990). Effects of errors in choice reaction tasks on the ERP under focused and divided attention. In C. H. M. Brunia, A. W. K. Gaillard, \& A. Kok (Eds.), Psychophysiological brain research (Vol. 1, pp. 192-195). Tilberg, the Netherlands: Tilberg University Press.

Falkenstein, M., Hohnsbein, J., Hoormann, J., \& Blanke, L. (1991). Effects of crossmodal divided attention on late ERP components: II. Error processing in choice reaction tasks. Electroencephalography and Clinical Neurophysiology, 78, 447-455.

Falkenstein, M., Hoormann, J., Christ, S., \& Hohnsbein, J. (2000). ERP components on reaction errors and their functional significance: A tutorial. Biological Psychology, 51, 87-107.

Falkenstein, M., Hoormann, J., \& Hohnsbein, J. (2001). Changes of errorrelated ERPs with age. Experimental Brain Research, 138, 258-262.

Gehring, W. J., Goss, B., Coles, M. G. H., Meyer, D. E., \& Donchin, E. (1993). A neural system for error detection and compensation. Psychological Science, 4, 385-390.

Gehring, W. J., \& Knight, R. T. (2000). Prefrontal-cingulate interactions in action monitoring. Nature Neuroscience, 3, 516-520.

Herrmann, M. J., Römmler, J., Ehlis, A., Heidrich, A., \& Fallgatter, A. J. (2004). Source localization (LORETA) of the error-relatednegativity (ERN/Ne) and positivity (Pe). Cognitive Brain Research, 20, 294-299.

Hillman, C. H., Buck, S. M., Themanson, J. T., Pontifex, M. B., \& Castelli, D. M. (2009). Aerobic fitness and cognitive development: Event-related brain potential and task performance indices of executive control in preadolescent children. Developmental Psychology, $45,114-129$.

Hillman, C. H., Motl, R. W., Pontifex, M. B., Posthuma, D., Stubbe, J. H., Boomsma, D. I., \& de Geus, E. J. C. (2006). Physical activity and cognitive function in a cross-section of younger and older communitydwelling individuals. Health Psychology, 25, 678-687.

Hinton, P. R., Brownlow, C., McMurray, I., \& Cozens, B. (2004). SPSS explained. East Sussex, UK: Routledge.

Holroyd, C. B., \& Coles, M. G. H. (2002). The neural basis of human error processing: Reinforcement learning, dopamine, and the errorrelated negativity. Psychological Review, 109, 679-709.

Hultsch, D. F., \& MacDonald, S. W. S. (2004). Intraindividual variability in performance as a theoretical window onto cognitive aging. In R. A. Dixon, L. Backman, \& L.-G. Nilsson (Eds.), New frontiers in cognitive aging (pp. 65-88). New York: Oxford University Press.

Liotti, M., Pliszka, S. R., Perez, R., Kothmann, D., \& Woldorff, M. G. (2005). Abnormal brain activity related to performance monitoring and error detection in children with ADHD. Cortex, 41, 377-388.

Mathalon, D. H., Bennett, A., Askari, N., Gray, E. M., Rosenbloom, M. J., \& Ford, J. M. (2003). Response-monitoring dysfunction in aging and Alzheimer's disease: An event-related potential study. Neurobiology of Aging, 24, 675-685.

Mathewson, K. J., Dywan, J., \& Segalowitz, S. J. (2005). Brain bases of error-related ERPs as influenced by age and task. Biological Psychology, 70, 88-104.

Miltner, W. H. R., Lemke, U., Weiss, T., Holroyd, C., Scheffers, M. K., \& Coles, M. G. H. (2003). Implementation of error-processing in the human anterior cingulated cortex: A source analysis of the magnetic equivalent of the error-related negativity. Biological Psychology, 64, $157-166$.

Nieuwenhuis, S., Ridderinkhof, K. R., Blom, J., Band, G. P. H., \& Kok, A. (2001). Error-related brain potentials are differentially related to awareness of response errors: Evidence from an antisaccade task. Psychophysiology, 38, 752-760.

Nieuwenhuis, S., Ridderinkhof, K. R., Talsma, D., Coles, M. G. H., Holroyd, C. B., Kok, A., \& van der Molen, M. W. (2002). A computational account of altered error processing in older age: Dopamine and the error-related negativity. Cognitive, Affective, and Behavioral Neuroscience, 2, 19-36.

Olvet, D., \& Hajcak, G. (2009). The stability of error-related brain activity with increasing trials. Psychophysiology, 46, 1-5.

Overbeek, T. J. M., Nieuwenhuis, S., \& Ridderinkhof, K. R. (2005). Dissociable components of error processing: On the functional significance of the Pe vis-à-vis the ERN/Ne. Journal of Psychophysiology, 19, 319-329.

Pontifex, M. B., \& Hillman, C. H. (2007). Neuroelectric and behavioral indices of interference control during acute cycling. Clinical Neurophysiology, 118, 570-580.

Ridderinkhof, K. R., Ramautar, J. R., \& Wijnen, J. G. (2009). To Pe or not to Pe: A P3-like ERP component reflecting the processing of response errors. Psychophysiology, 46, 531-538.

Santesso, D. L., Segalowitz, S. J., \& Schmidt, L. A. (2006). Error-related electrocortical responses are enhanced in children with obsessivecompulsive behaviors. Developmental Neuropsychology, 29, 431-445.

Siegler, R. S. (1994). Cognitive variability: A key to understanding cognitive development. Current Directions in Psychological Science, 3, $1-5$.

Themanson, J. R., Hillman, C. H., \& Curtin, J. J. (2006). Age and physical activity influences on action monitoring during task switching. Neurobiology of Aging, 27, 1335-1345.

Themanson, J. R., Hillman, C. H., McAuley, E., Buck, S. M., Doerksen, S. E., Morris, K. S., \& Pontifex, M. B. (2008). Self-efficacy effects on neuroelectric and behavioral indices of action monitoring in older adults. Neurobiology of Aging, 29, 1111-1122.

van Veen, V., \& Carter, C. S. (2002). The timing of action-monitoring processes in the anterior cingulated cortex. Journal of Cognitive Neuroscience, 14, 593-602.

Wiersema, J. R., van der Meere, J. J., \& Roeyers, H. (2007). Developmental changes in error monitoring: An event-related potential study. Neuropsychologia, 45, 1649-1657.

(ReCEIVEd June 17, 2009; ACCEPTED July 27, 2009) 